\title{
Digitalization in the Labor Market in Russia
}

\author{
Irina Omelchenko ${ }^{1}$, Galina Antonova ${ }^{1}$, Marina Danilina ${ }^{1,2,3, *}$, Sergey Popkov ${ }^{1}$, and Ludmila \\ Botasheva $^{2}$ \\ ${ }^{1}$ All-Russian Research Institute VNII of Labor, Ministry of Labor, Moscow, Russia \\ ${ }^{2}$ Financial University under the Government of the Russian Federation, Moscow, Russia \\ ${ }^{3}$ Plekhanov Russian University of Economics (PRUE), Moscow, Russia
}

\begin{abstract}
In recent years the labor market experienced a number of changes. On the basis of the statistical and content analysis the authors research the main trends and indicators of the labor market. The modern economy and labor market are more and more clearly moving along the path of digitalization - the widespread introduction of the latest generation of advanced technologies (information, communication, robotics, artificial intelligence, etc.) into economic activities, completely changing the usual business processes. The pandemics of COVID19 has shown that the digitalization can be actively used in the companies and can change the situation in the labor market. Thus, digitalization affects all spheres of economic and social life, affects the demand for various categories of workers of various qualifications.
\end{abstract}

\section{Introduction}

The main trends and the current state of the Russian labor market, as well as the processes taking place in the sphere of employment of the population, are due both to the influence of negative socio-economic and geopolitical factors (the consequences of the crisis in the economy, a slow recovery of incomes of the population, the effect of sanctions), and unfavorable for the economy. countries with long-term demographic trends.

The main demographic risks for the country's economy in the medium and long term are the continuing reduction in the size of the main age group that provides labor supply in the labor market, namely, the working-age population, the deterioration of its age structure due to the continuing decline in the inflow of the cohort of young people entering the labor market. working age, with a simultaneous increase in the proportion of older ages (including due to a gradual increase in the boundaries of working age).

\section{Main trends of the labor market in russia}

Let's analyze the main trends in the labor market in recent years. In eight years, from 2010 to 2018 , the working-age population declined by 6 million. At the same time, the peculiarity of the current situation lies in the fact that despite the continuing tangible

\footnotetext{
* Corresponding author: marinadanilina@yandex.ru
} 
decrease in the population of working age, the labor force remained practically stable until the beginning of 2019, slightly decreasing (within $0.1-0.7$ percent) after 2016 . This stability was provided mainly due to the activity of "young pensioners" who remained in the labor market after they reached retirement age [1]. According to the results of the Labor Force Survey (LFS Rosstat) in 2018, the economically active population of the Russian Federation aged 15 years and over was 76.2 million people, or $62.8 \%$ of the total population of this age. Compared to 2017, it decreased by 95 thousand people, or $0.1 \%$ [1]. According to the results of the first half of 2019, compared to the same period in 2018 , Rosstat recorded a decrease in the number of labor force by $1.2 \%$, that is, at a slightly faster pace than in previous years, which may indicate the emergence of a trend towards a reduction in the number of labor force in conditions maintaining the old boundaries of working age. A delay in the labor market of a part of citizens who planned to leave work when they reach the previous retirement age, will apparently change this trend, that is, lead to stabilization or some growth in the number of labor force in the medium term.

In recent years, high indicators have remained - the level of participation of the population in the labor force and the level of employment of the population. So, in 2018, the level of participation of the population in the labor force was $68.9 \%$, (within the boundaries of 15-72 years). The peak of this indicator - a record of average annual values for the entire observation period - was observed in $2016-69.5 \%$ [1].

The level of participation of the population in the labor force (taking into account persons over 72 years old) during 2017-2018 remained at the same level $-62.8 \%$ [1].

The situation with the preservation of high indicators of economic activity of the population against the background of a decrease in the number of people of working age is largely explained by changes in the age structure of the country's population in recent years. In the process of a generational change, only for the period from 2012 to 2018, the cohort of young people (15 years - 24 years) lost $24.5 \%$ or more than 4.7 million people. As a result, their share in the total population decreased quite noticeably (from $17.4 \%$ to $12 \%$ ).

Accordingly, the number and proportion of economically active youth in the labor force decreased. So, according to Rosstat (LFS), in the first half of 2019, the number of economically active youth in the labor force decreased by almost two times (by 4.2 million people), and the share - respectively, from $11.7 \%$ to $6.2 \%$ [1].

As you know, the level of economic activity of young people in connection with their studies, as well as with the birth of children and the need to care for them is traditionally significantly lower than that of people over 30 . Therefore, the decrease in the proportion of young people with low economic activity in the labor force, with a simultaneous absolute and relative increase in the number of people of the most active working age (30-44 years), as well as an increase in the economic activity of people over working age, provided a high level of economic activity of the population as a whole.

The employment rate of the population (within the boundaries of 15-72 years) on average for the period 2016-2018 remained unchanged and amounted to $65.6 \%$ at the end of 2018. Only in the first half of 2019, compared to the same period in 2018, the employment rate decreased by one percent, but it is too early to speak of a downward trend. It should be noted that the inclusion in the Labor Force Survey (LFS) of persons over 72 years old (since 2017) was most noticeably reflected in the indicator-indicator "employment rate". The value of the new indicator, calculated for the entire population over 15 years old, is noticeably lower in 2017 and 2018. it was, respectively, 59.5\% and $59.8 \%[1]$.

In 2018, the situation with employment in the labor market was slightly better than in 2017, according to sample surveys (LFS), the number of people employed in the economy during 2018 increased from 72.3 to 72.5 million people (by $0,2 \%$ ). At the same time, 
$45.0 \%$ of the total number of employed were concentrated in large and medium-sized enterprises and organizations.

According to Rosstat surveys, the number of unemployed, calculated according to the ILO methodology, slightly decreased in 2018 compared to the previous year and amounted to 3.7 million people. The overall unemployment rate in 2018 was $4.8 \%$ of the economically active population [1].

The number of unemployed citizens in the registered labor market who are registered with the employment service also decreased - from 0.76 million people at the end of December 2017 to 0.69 million people in the same period in 2019 [2].

According to the Rosstat survey for 2018, of the total number of unemployed, calculated according to the ILO methodology, 27.3\% (1 million people) had no work experience. Compared to 2017, this indicator increased by 1.3 percentage points. Among the unemployed with work experience, more than a third $(37 \%)$ are persons who quit their jobs of their own accord and $21.2 \%$ are persons who left their last job due to staff cuts. Compared to 2017, the share of the unemployed who left their jobs due to staff cuts decreased by 0.8 percentage points [1].

The indicators characterizing the length of stay in unemployment improved slightly in 2018 compared to the previous year. Thus, the average time spent looking for a job by the unemployed decreased by 0.2 months, amounting to 7.4 months. $28.6 \%$ of the unemployed had one or more years of unemployment (in 2017 - 30.4\%). Long-term unemployment is concentrated mainly in rural areas. Although the share of long-term (more than a year) unemployed among rural residents has decreased over the past year by 3.6 percentage points, it is still extremely high - 33.1\% (2018). For comparison, the share of stagnant unemployment among urban residents is $26.1 \%$ [1].

The age composition of the unemployed in the general labor market is quite young - the average age was 36.1 years in 2018. Youth under 25 years old among the unemployed accounted for $22.4 \%$; persons aged 55 and over - 10.4\%. Most of the unemployed - $60 \%$ had a professional education, including higher - more than $20 \%$ [1].

\section{Labor Market and Digitalization}

Let's analyze the main trends in the labor market in recent years. In eight years However, in this industry, too, largely under the influence of digitalization, in the last two years (from the second quarter of 2017) there has been a negative trend in the number of employed: the reduction was 278 thousand people, or $2.1 \%$. The release of personnel in the field of trade was largely influenced by the increasing spread of the transition of trade to Internet customer service, thereby reducing the need to create outlets; retail chains automate many processes: for example, automatic generation of store orders to a warehouse; electronic document management; simplification of the procedure for accepting goods through automated systems, etc.

Another area where the number of employees has significantly increased over ten years (from 2008 to 2018) is financial and insurance activities (by $24.9 \%$ or 0.3 million people). It should be noted that in this area, in recent years, as well as in trade, due to digitalization and the transition to online services, there has been a release of employees of service and support departments: clerks, call center operators, accountants, legal and human resources workers.

Nevertheless, the increase in the number is due to the involvement of more qualified specialists in this field of activity, ensuring the optimization of business processes in organizations of this foreign economic activity, as well as the creation and maintenance of the operation of remote services, into which a significant proportion of services have been transferred due to digitalization. 
The number of people employed in professional, scientific and technical activities in the last two years alone, from 2008 to 2018 , increased by 0.9 million people, or $27.8 \%$. At the same time, in such a type of activity as "research and development", which ensures the quality of economic growth, the generation of new knowledge, the dissemination of information, the accumulation of human capital, and the demand for the most qualified labor force, the number of employed is gradually decreasing.

So, in only two years from 2017 to 2018. the number of people employed in research and development decreased from 902.4 thousand people in 2017 to 887.7 thousand people in 2018 (by 1.6\%), accounting for $1.2 \%$ of the total number of people employed in the economy Russia.

The number of people employed in the education sector has a positive trend; however, over ten years (from 2008 to 2018 ) it increased by only 0.4 million people (6.4\%), and the share of people employed in this area only slightly exceeded the 2008 level. and amounted to $9.5 \%$.

The growth in the number of people in the healthcare sector over ten years amounted to $13.2 \%$, or 0.7 million people. The share of people employed in education in the total number of people employed in the economy also slightly increased from 2008 to 2018. and amounted to $8 \%$.

The modern economy is more and more clearly moving along the path of digitalization the widespread introduction of the latest generation of advanced technologies (information, communication, robotics, artificial intelligence, etc.) into economic activities, completely changing the usual business processes. The pandemics of COVID19 has shown that the digitalization can be actively used in the companies and can change the situation in the labor market. Thus, digitalization affects all spheres of economic and social life, affects the demand for various categories of workers of various qualifications.

The most affected by the epidemic were tourism and restaurants (vacancies fell by $78 \%$ compared to February), sports, fitness and beauty (a drop of 73\%), services for the population (a drop of 68\%), arts, entertainment and mass media (a drop by 64\%), marketing and advertising (54\% drop). Demand is gradually recovering everywhere, but taking into account a large drop at this time.

\section{Results}

Thus, in 2017 and 2018, the situation on the national labor market was determined by the growth of employment in the economy and the expansion of demand for labor, which generally had a favorable effect on the situation with unemployment. However, the situation on the labor market remains unbalanced. In a number of regions, unemployment rates are significantly higher than the average, while the economy continues to experience a shortage of qualified personnel.

The analysis of the territorial structure of both total and registered unemployment reveals the persistence of its focal character and the existence of significant territorial disparities in local labor markets in most constituent entities of the Russian Federation, especially in rural areas. At the same time, unemployment is predominantly structural in nature. In the face of growing demand for labor and an increase in the number of job vacancies, a structural imbalance between supply and demand remains, primarily in terms of professional and qualification characteristics. 


\section{Conclusion}

In order to conclude, the modernization of production and the transition to new technologies have led to an increase in employers' requirements for the quality of the workforce. At the same time, the structure of professional training does not always correspond to the demands of the labor market. As a result, in terms of its quantitative characteristics, the supply of labor in the labor market is capable of satisfying the needs of employers, however, the demand of employers increasingly remains unsatisfied, which indicates the problem of a mismatch between demand and supply in terms of qualitative parameters.

Based on the analysis of the dynamics of the number of employed by types of economic activity, it should be noted that a significant increase in the number of employees in the non-production sector and a decrease in employment in industrial production affected their share in the structure of employed in the economy. This primarily applies to retail and wholesale trade, where the number of employees in the ten years from 2008 to 2018 increased by 0.9 million people, or $8.1 \%$, and the share of the number of employees increased from $15 \%$ in 2008 to almost $16 \%$ in 2018.

\section{References}

1. Quarterly statistical bulletin "Labor Force Survey", IIC "Statistics of Russia", 2010 -1st quarter of 2019, http://www.gks.ru/

2. Form No. 2-T (employment) "Information on the provision of public services in the field of promoting employment of the population", Federal Service for Labor and Employment, January-December 2017 and 2018, 1st half of 2019

3. Statistical collection "Labor force, employment and unemployment in Russia (based on the results of sample surveys of the labor force) (2018)

4. The base of official statistical information "Unified Interdepartmental Information and Statistical System (EMISS)", https://www.fedstat.ru

5. Statistical bulletin "Information on the number and needs of organizations for workers by professional groups as of October 31, 2018", Federal State Statistics Service (Rosstat) (2018) https://www.gks.ru/

6. Law of the Russian Federation "On employment of the population in the Russian Federation" of 19.04.1991 N 1032-1 (as amended on 11.12.2018)

7. Monitoring and assessment of the quality and availability of public services in the field of promoting employment of the population (based on the results of the activities of the employment service in 2018), https://rosmintrud.ru/ 